\title{
The pathophysiology of chronic constipation
}

\author{
Christopher N Andrews MD MSc FRCPC ${ }^{1}$, Martin Storr MD ${ }^{1,2}$
}

\begin{abstract}
CN Andrews, M Storr. The pathophysiology of chronic constipation. Can J Gastroenterol 2011;25(Suppl B):16B-21B.

Constipation is broadly defined as an unsatisfactory defecation characterized by infrequent stools, difficult stool passage or both. The common approach to the pathophysiology of constipation groups the disorder into primary and secondary causes. Primary causes are intrinsic problems of colonic or anorectal function, whereas secondary causes are related to organic disease, systemic disease or medications. The normal process of colonic transit and defecation is discussed, and the etiology of constipation is reviewed.
\end{abstract}

Key Words: Colonic transit; Constipation; Defecation disorders; Dyssynergia

\author{
Freedom of the bowels is the most precious, perhaps \\ even the most essential, of all freedoms - one without \\ which little can be accomplished. \\ - Émile Gautier, 1909
}

$\mathrm{C}_{\mathrm{tan}}^{\mathrm{o}}$ onstipation is broadly defined as unsatisfactory defecation characterized by infrequent stools, difficult stool passage or both (1). Constipation is prevalent in North America, with most studies estimating a prevalence of $12 \%$ to $19 \%$ (2), and some Canadian national data suggesting rates up to $27 \%$ (3). The pathophysiology of constipation is multifactorial and classification schemes can be confusing. The common approach groups constipation into primary and secondary causes. Primary causes are intrinsic problems of colonic or anorectal function, whereas secondary causes are related to organic disease, systemic disease or medications. The classification becomes confusing because secondary causes are typically ruled out first through history, physical examination and diagnostic testing.

The present article discusses the normal process of colonic transit and defecation, followed by a review of the etiology of constipation.

\section{Water absorption}

\section{PHYSIOLOGY OF COLONIC FUNCTION}

The colon receives approximately $1.5 \mathrm{~L}$ of liquid effluent daily from the small intestine, with $200 \mathrm{~mL}$ to $400 \mathrm{~mL}$ excreted in the stool. The functions of the colon are to absorb fluid and transport waste to the rectum, where it is expelled or stored until defecation is convenient. Removal of water from the fecal slurry is time dependent and actively regulated, and can be substantially increased in dehydration states (4). Sodium is actively reabsorbed from luminal content through several active transport channels, with water following passively in response to osmotic gradients. Conversely, colonic secretion is mediated through chloride channels (eg, cystic fibrosis transmembrane conductance regulator [CFTR]), which are generally quiescent, leading to a net reabsorption of electrolytes and fluid (4). Thus, stool that remains in the colon longer will become drier, which can lead to scybalation (pebble-like stools) and impaction if the stool becomes too large and hard to pass through the anal canal. Cholera toxin,

\section{La physiopathologie de la constipation chronique}

La constipation est largement définie comme une défécation insatisfaisante caractérisée par des selles peu fréquentes, un passage difficile des selles ou ces deux problèmes. En général, la physiopathologie de la constipation classe le problème en causes primaires et secondaires. Les causes primaires sont des problèmes intrinsèques de la fonction colique ou anorectale, tandis que les causes secondaires sont liées à une maladie organique, une maladie systémique ou des médicaments. Le processus normal de transit du côlon et de défécation est exposé, et l'étiologie de la constipation est analysée. which selectively stimulates the CFTR channel, can produce overwhelming secretory diarrhea. In patients with cystic fibrosis, the CFTR channel is nonfunctional, which leads to overly dry stools and constipation. Lubiprostone, a selective CFTR agonist and intestinal secretagogue, is widely used in the United States for constipation, but is not available in Canada.

\section{Colonic motility}

On a macro level, two characteristic movements in the colon achieve the absorptive and transport functions (5). Repetitive nonpropulsive contractions move stool in a manner that aids in absorption and mixing of content. Larger, coordinated contractions (known as highamplitude propagated contractions [HAPCs]) bring stool forward in mass movements from the ascending colon down to the left colon (Figure 1). HAPCs typically occur in the morning soon after awakening, and may be accentuated by other cues or triggers such as eating or drinking (related to the gastrocolic reflex in infants), mirroring the common experience of the urge to defecate during this time. Of note, colonic motility is strongly attenuated during sleep to avoid incontinence; thus nocturnal bowel movements or anal leakage is significantly abnormal. When stool enters the rectum, it causes distension and a conscious perception of the urge to defecate. If the time is not appropriate, the rectum accommodates to store the stool temporarily, resulting in the dissipation of the urge and propagating contractions. Normal colonic transit in adults ranges from $20 \mathrm{~h}$ to $72 \mathrm{~h}(6,7)$. The frequency of HAPCs is decreased in constipation and likely plays a significant role in its pathophysiology (7).

On a molecular level, gut motility is a complex process that includes several layers of neural and hormonal control from the colon up to the central nervous system (8). On a simplified level, peristalsis, the major movement theme of the gut, is mediated predominantly through the neurotransmitter serotonin (5-hydroxytryptamine [5HT]). When a food or stool bolus distends the gut wall, enterochromaffin cells release 5HT. This causes a local reflex mediated through enteric nerves, releasing stimulating neurotransmitters (such as acetylcholine, which causes muscle contraction) behind the bolus and inhibitory

${ }^{1}$ Centre for Digestive Motility, Division of Gastroenterology, Department of Medicine, University of Calgary, Alberta; ${ }^{2}$ Ludwig Maximilian University, Munich, Germany

Correspondence: Dr Christopher N Andrews, Division of Gastroenterology, University of Calgary Medical Clinic, 3330 Hospital Drive Northwest,

Calgary, Alberta T2N 4N1. Telephone 403-592-5015, fax 403-592-5090, e-mail candrews@ucalgary.ca

Received for publication June 2, 2011. Accepted June 10, 2011 


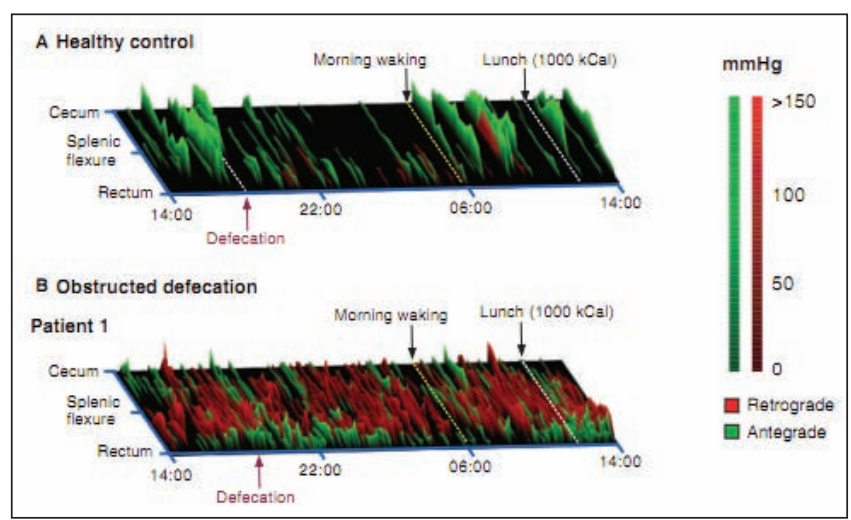

Figure 1) Twenty-four hour high-resolution colonic manometry plots in a female healthy control (A) and in a female patient with a defecation disorder (B). The plots are spatiotemporal maps of antegrade (green) and retrograde (red) colonic propagating contractions. In (A), the high amplitude propagating contractions (HAPCs) are clearly seen before defecation and on awakening in the morning. In comparison, the propagated motor patterns in patients with defecation disorders (B) show an increased frequency of lowamplitude antegrade and retrograde propagating sequences, with a reduced frequency of HAPC. Furthermore, in (B), no nocturnal suppression of contractile activity nor colonic responses to a high-calorie meal are seen. Adapted with permission from reference 49

neurotransmitters (such as nitric oxide, which causes muscle relaxation) in front of the bolus; thus, the bolus is propelled forward along the gastrointestinal tract. For example, disorders of $5 \mathrm{HT}$ overproduction, such as carcinoid syndrome, lead to substantial diarrhea. This complex algorithm requires intact enteroendocrine, neural and muscle machinery to function correctly.

The gut has seven $5 \mathrm{HT}$ receptor subtypes, of which $5 \mathrm{HT}_{4}$ and $5 \mathrm{HT}_{3}$ are the most significant. The $5 \mathrm{HT}_{4}$ receptor drives the gut's peristaltic response to $5 \mathrm{HT}$, and $5 \mathrm{HT}_{4}$ agonists such as cisapride, tegaserod and prucalopride are, or have been, widely used enterokinetic medications. The $5 \mathrm{HT}_{3}$ receptor, on the other hand, is more predominantly involved in gut sensation and central processing of this information, with $5 \mathrm{HT}_{3}$ antagonist drugs such as ondansetron being commonly used in antiemetic therapy.

\section{Mechanism of laxatives}

Using this framework of normal colonic physiology, laxatives may be broadly grouped into osmotic and stimulant types. Osmotic laxatives, such as 'Milk of Magnesia' (Philips, USA), lactulose and polyethylene glycol 3350, all draw water into the colonic lumen, leading to softer stool and increased defecation frequency. Lubiprostone (not available in Canada) increases colonic fluid by stimulating chloride secretion into the lumen. Stimulant laxatives include irritant substances (such as bisacodyl, senna products and cascara) that directly stimulate afferent nerves or muscle in the gut wall, and enterokinetics, which induce peristalsis (including cisapride, tegaserod and prucalopride).

\section{PHYSIOLOGY OF DEFECATION}

Normal defecation and maintenance of continence is a sophisticated process requiring rectal filling, awareness of rectal filling, and the ability to propel the stool and relax the pelvic floor muscles in a coordinated fashion (9). Several factors act in concert to maintain fecal continence. Anatomical factors include the anal sphincters and puborectalis muscles (ie, the pelvic floor) and rectal curvatures (ie, the rectoanal angle). Transverse rectal folds and hemorrhoidal tissue in the anal canal also serve as passive barriers.

The internal anal sphincter, which is not under conscious control, is comprised of smooth muscle and maintains $70 \%$ of the resting anal tone. The external anal sphincter (EAS) is under voluntary control, is comprised of striated muscle and accounts for the remaining $30 \%$ of

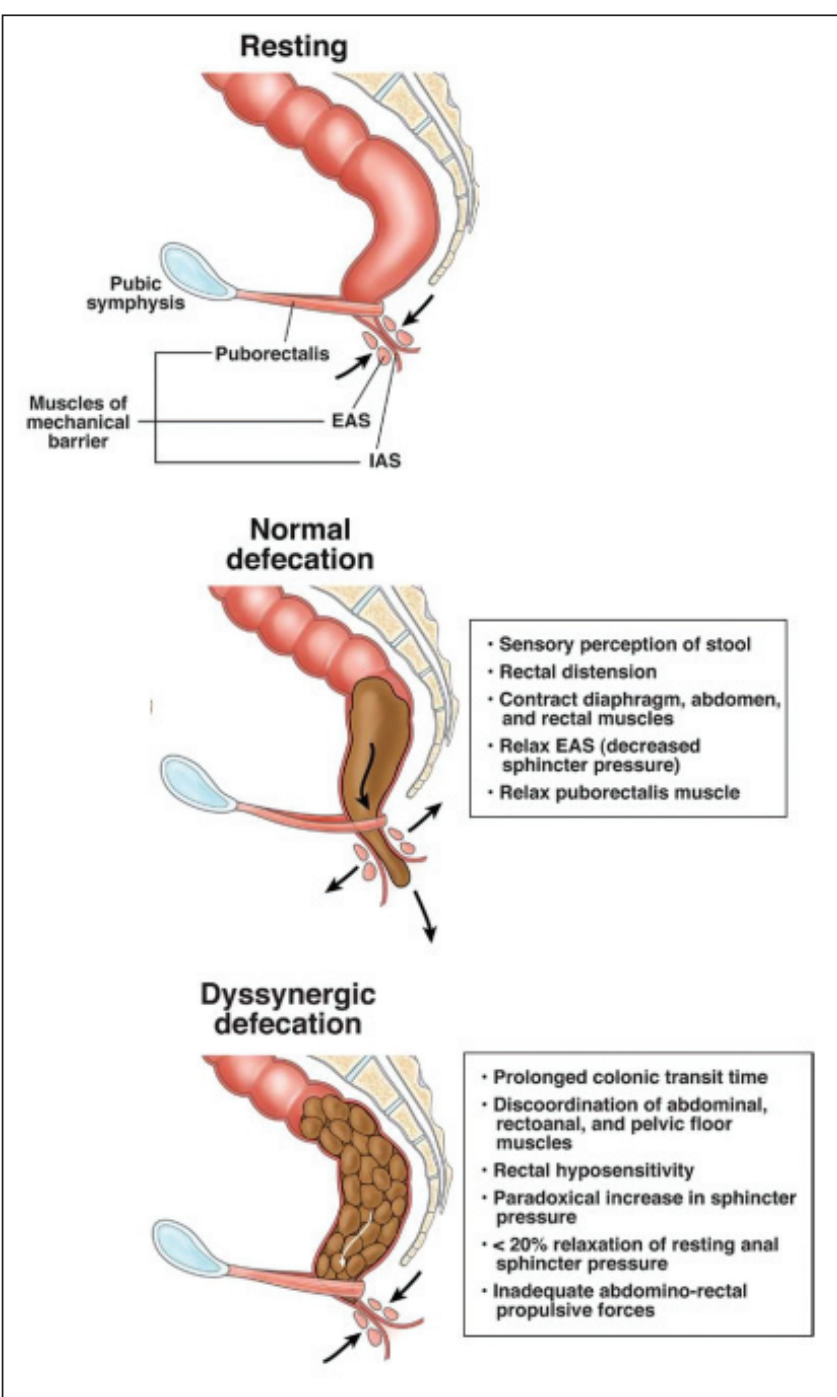

Figure 2) Normal anatomy and physiology of the pelvic floor in the sagittal plane at rest, during normal defecation and during dyssynergic defecation. The resting profile shows the arrangement of the internal and external anal sphincters (IAS and EAS, respectively), as well as the puborectalis muscle. During defecation, the anal sphincters and the puborectalis relax and the abdominal and rectal contraction generate a push force to empty the rectum of stool. In patients with dyssynergia, the push effort or anal relaxation may be impaired, or the anal sphincters and puborectalis may not relax during attempted defecation, leading to incoordination (ie, dyssynergia) and stool retention. Adapted with permission from reference 10

resting sphincter tone. The puborectalis maintains the rectoanal angle at rest, and contracts further to reduce the angle when subjects squeeze. Rectal distension from stool or gas induces reflex relaxation of the internal anal sphincter, known as the rectoanal inhibitory reflex (RAIR). The RAIR is mediated through the enteric nervous system and does not require any external control from the peripheral or central nervous system. Hirschsprung's disease, a congenital disorder that causes truncation of innervation of the distal colon, can be definitively ruled out by observation of the RAIR on anorectal manometry.

During normal defecation, stool distends the rectum, causes reflex relaxation of the internal anal sphincter and produces the perception of the need to defecate (Figure 2). Sensory mechanisms in the anal canal, which are not well understood, enable determination of whether rectal content is gas or stool. If defecation is inconvenient, the desire to defecate prompts voluntary contraction of the EAS. The 
TABLE 1

Pathophysiology of chronic constipation

\begin{tabular}{ll}
\hline $\begin{array}{l}\text { Primary causes } \\
\text { Normal transit (most }\end{array}$ & Secondary causes \\
Slow transit & Medications \\
Evacuation disorder & Obstruction (eg, cancer, stricture) \\
& Metabolic (eg, hypothyroid, hypercalcemia) \\
& Neurological (eg, parkinsonism, multiple \\
& sclerosis) \\
& Systemic (eg, scleroderma, amyloidosis) \\
& Psychiatric (eg, depression, eating disorders) \\
\hline
\end{tabular}

desire to defecate dissipates as the rectum relaxes, allowing more stool to be accommodated. If the time is appropriate, the subject sits or squats, holds his or her breath, contracts the diaphragm, the abdominal and rectal muscles, and simultaneously relaxes the EAS and puborectalis muscle (10). These actions open the anus and expel stool. Thus, sensory perception and physiological coordination are integral components of anorectal function.

\section{CONSTIPATION}

The causes of constipation are varied and may be multifactorial. The common approach groups constipation into primary and secondary causes. Primary causes are intrinsic problems of colonic or anorectal function, whereas secondary causes are related to organic disease, systemic disease or medications.

\section{Primary constipation}

Primary forms of constipation arise from intrinsic defects in colonic function or malfunction of the defecation process. These causes are typically considered after secondary causes of constipation are ruled out, often by history (Table 1). When no obvious causes or alarm features are identified on history, empirical treatment often starts with fibre supplements and/or laxatives. If treatment is successful, no further workup is generally necessary.

If further characterization of a suspected primary cause of constipation is necessary, localization of the problem - either to the colon or to the anorectum - is required. This is typically achieved with a colonic transit test. The most common method is to use radiopaque markers (ie, Sitzmarks [Konsyl Pharmaceuticals Inc, USA]) administered in a standardized fashion $(11,12)$. The simplest of the methods uses a single capsule of markers that is ingested. Five days $(120 \mathrm{~h})$ later, a single flat plate $\mathrm{x}$-ray is taken, the markers are counted and the location described. Patients are required to discontinue all laxatives during the five-day study period. The retention of more than $20 \%$ of the markers at day 5 is considered to be abnormal. The test provides a rough approximation of colon transit time and can be administered in any medical imaging facility. Many other methods have been described, including multiple markers taken on subsequent days (7). Multiple marker tests may also provide information on the etiology of the retention (ie, markers grouped in the rectosigmoid suggests an outlet problem, whereas markers spread diffusely throughout the colon suggest slow colonic transit); however, these methods are not as well standardized. Scintigraphic transit tests (13) and wireless motility capsule studies (14) have been well characterized and are reliable, but not widely available.

\section{Normal-transit constipation}

Normal-transit constipation (otherwise known as 'functional' constipation) is the most common form of constipation seen by clinicians. The formal Rome III criteria for functional constipation are presented in Table 2. In this situation, patients report symptoms they believe are consistent with constipation such as the presence of hard stools or a perceived difficulty with evacuation (15). However, on testing, stool transit is not delayed and the stool frequency is often within the normal range $(3,16)$. Patients may experience bloating and abdominal
TABLE 2

Rome III criteria for functional constipation

Must include two or more of the following:
Straining*
Lumpy or hard stools*
Sensation of incomplete evacuation*
Sensation of anorectal obstruction/blockage*
Manual manoeuvres to facilitate defecation (eg, digital evacuation, support
of the pelvic floor)
$<3$ defecations/week
Loose stool rarely present without the use of laxatives
Insufficient criteria for irritable bowel syndrome with constipation

Symptoms must be present for $\geq 3$ months, with onset $\geq 6$ months before diagnosis. *Present in $\geq 25 \%$ of defecations. Adapted from reference 16

pain or discomfort, will frequently meet criteria for irritable bowel syndrome with constipation (IBS-C) (16) and may exhibit increased psychosocial distress (17). Symptoms of functional constipation typically respond to therapy with dietary fibre alone or with the addition of an osmotic laxative or enterokinetic (18). Because most patients are treated empirically and respond well, they typically will not require a formal transit test, and have also been diagnosed as 'simple' or 'fibre deficiency' constipation. In general, if empirical therapy fails, further evaluation is suggested to rule out other primary causes of constipation.

\section{Slow-transit constipation}

Slow-transit constipation (STC) causes infrequent bowel movements (typically less than once per week) and is most common in young women (19). Often, patients do not feel the urge to defecate and may complain of associated bloating and abdominal discomfort. As the name suggests, colonic transit time is prolonged in these patients, and frequency of HAPCs is reduced (7) (Figure 1).

'Colonic inertia' is a term used for a subset of patients with typically severe slow colonic transit, and who do not show an increase in motor activity after meals or after the administration of stimulants such as bisacodyl or cholinergic agents (20). However, definitions of colonic inertia are variable, and this classification may not alter therapy significantly (20).

STC is believed to be a neuromuscular disorder of the colon. Studies have shown decreased numbers of interstitial cells of Cajal (ICC) (21) and alterations in the number of myenteric plexus neurons expressing the excitatory neurotransmitter substance $P(22)$ in the gut wall of patients with this disorder. The recent London classification of gastrointestinal neuromuscular diseases also lists hypoganglionosis, inflammatory neuropathy and degenerative leiomyopathy as other causes of STC (23). Because our understanding of these disorders is only emerging, no therapies have yet been directed at the underlying etiology. Treatment typically uses an aggressive laxative regimen. To complicate matters further, chronic high-dose stimulant laxative use itself may slow colonic transit, leading to a potentially large subset of (previously) normal-transit constipation or IBS patients using laxatives who appear to have STC. Select patients with STC may respond well to subtotal colectomy and ileorectal anastomosis, provided there is no significant pelvic floor dysfunction or dyssynergia (24).

\section{Defecation disorders}

Defecation disorders (DDs) are a group of functional and anatomical abnormalities of the anorectum that lead to symptoms of constipation. Clinically, patients with DDs present with significant straining, often spending large amounts of time on the toilet daily. Manual rectal evacuation using a finger, position changes or frequent enema use is common. Frequently, laxatives are highly ineffective, and DD patients may even have difficulty evacuating liquid stools. Pelvic floor tone may be constantly increased, which can lead to hemorrhoid formation 
and anal fissuring, which can become chronic. Conversely, prolonged avoidance of defecation due to pain associated with anal fissure may result in DDs. Structural abnormalities, such as rectal intussusception or prolapse, rectocele and excessive perineal descent (descending perineum syndrome), are less common causes of DDs.

Dyssynergia, probably the most common functional DD, is an acquired behavioural DD. In most subjects, dyssynergia is a result of poor toileting habits, painful defecation, obstetric or back injury, or brain-gut dysfunction $(25,26)$. Some patients have a history of sexual or physical abuse, or an eating disorder. In children, fecal retention may result in encopresis due to leakage of liquid stool around impacted stool (27). Patients with dyssynergia are unable to coordinate the abdominal, rectoanal and pelvic floor muscles during defecation, and may also demonstrate rectal hyposensitivity (26). Other terms have been used to describe dyssynergia, including anismus, pelvic floor dysfunction, puborectalis spasm and outlet constipation. Although each of these terms has particular nuances pertaining to the specific etiology of the dyssynergia, many clinicians use them interchangeably.

To fulfill the formal diagnostic criteria for dyssynergic defecation (26), patients must:

1. Satisfy the symptomatic diagnostic criteria for chronic constipation (Rome III); and

2. Show a dyssynergic pattern of defecation, during repeated attempts to defecate with manometry, imaging or electromyography. (Dyssynergia is defined as a paradoxical increase in anal sphincter pressure [anal contraction] or less than $20 \%$ relaxation of the resting anal sphincter pressure or inadequate abdominorectal propulsive forces.)

3. Have one or more of the following:

- an inability to expel an artificial stool $(50 \mathrm{~mL}$ water-filled balloon) within $1 \mathrm{~min}$;

- prolonged colonic transit time; or

- an inability to evacuate, or $50 \%$ or more retention of barium during defecography.

It should be noted that prolonged colonic transit time can be seen in patients with DD and in patients with STC. With low specificity, it is clear that diagnosis of primary constipation subtypes often relies on more than a single functional test; detailed history is crucial. Furthermore, anorectal manometry and defecography (defecating proctography) may only be available in specialized centres. As the name suggests, anorectal manometry incorporates a manometric evaluation of the pressures of the anal canal during rest, squeeze and bearing down. Testing also typically includes assessments of rectal sensation using a balloon in the rectum. A final evaluation consists of a balloon expulsion test, in which the patient attempts to expel a rectal balloon filled with a standardized volume of water into a commode. This provides an objective assessment of the patient's ability to defecate because most normal patients should be able to expel the balloon. Anorectal manometry and balloon expulsion are generally considered to be the gold-standard test for the diagnosis of functional DDs (28).

Defecography involves placing a barium paste simulating stool into the rectum. The patient then attempts to defecate in a commode while undergoing fluoroscopy. Defecography provides useful information regarding the anatomical and, to a lesser degree, functional changes of the anorectum. It can reveal abnormalities that may not be clinically or endoscopically apparent, such as rectocele, mucosal intussusception, rectal prolapse or excessive perineal descent. Functional problems may be revealed as poor activation of the levator muscles, prolonged retention or inability to expel the barium. Defecography is particularly useful when a structural outlet problem is suspected.

If anorectal functional testing for DD is not available, it may be reasonable to proceed to physiotherapy (and biofeedback, if available) in which symptoms and other testing suggest a functional DD. Pelvic floor physiotherapy, with a focus on education and recoordination of the defecation manoeuvre, is available at most centres. There is no risk involved and the results are positive (26-29).

\section{Secondary constipation}

Drugs causing constipation: Constipation is a common side effect of many drugs, and a detailed medication history should be taken during the initial workup $(30,31)$.

Antihypertensive drugs such as clonidine, calcium antagonists, and ganglionic blockers reduce smooth muscle contractility and can cause constipation. In patients with constipation, these should be preferably replaced by beta-blockers, angiotensin-converting enzyme inhibitors, or angiotensin II receptor antagonists (32). Another group of drugs frequently associated with constipation are antidepressants, especially tricyclic antidepressants. Selective $5 \mathrm{HT}$ reuptake inhibitors and 5HT norepinephrine reuptake inhibitors are alternatives that are less associated with constipation and may be preferred in these patients (33).

Oral iron supplementation frequently causes constipation and, in patients in whom iron supplementation is necessary, intravenous supplementation of iron or the addition of a laxative may be options. Aluminum-containing drugs such as sucralfate and antacids can cause constipation, and these drugs may be replaced by proton pump inhibitors (34). Analgesics, such as opiates and cannabinoids, are especially notorious for causing constipation. Switching to a different class of analgesic drugs or using an opiate in combination with a peripherally active opiate receptor antagonist, such as naloxone or methylnaltrexone, may be considered (35).

Furthermore anti-Parkinson, antiepileptic and antipsychotic drugs are associated with constipation due to their anticholinergic and dopaminergic actions, and should be avoided or combined with the regular use of laxatives. Antihistamines, antispasmodics and vinca alkaloids are associated with constipation as a side effect and should be replaced $(30,31)$.

\section{NEUROLOGICAL DISORDERS AND CONSTIPATION}

Diseases that involve the nervous system may cause chronic constipation. These diseases include autonomic neuropathy, diabetes mellitus, and other endocrine diseases as well as rare causes such as Chagas disease and Hirschsprung's disease.

Among these conditions, diabetes can cause multiple gastrointestinal symptoms, especially gastroparesis and intestinal enteropathy. Intestinal enteropathy can cause diarrhea, constipation and fecal incontinence, alternation of symptoms or a combination of these. Although some studies have indicated that diabetic autonomic neuropathy that causes intestinal enteropathy may be the principal underlying mechanism, the exact causes of constipation in patients with diabetes are poorly defined. Constipation can be found in patients with type 1 and type 2 diabetes and is clearly more frequent compared with healthy individuals, although definite statistics regarding frequency are not available (36). Presently, it remains unclear why constipation is more frequent in female patients with diabetes than in males.

For patients with type 1 and type 2 diabetes, no single risk factor for the development of gastrointestinal complications has been identified; however, there are multiple studies investigating potential underlying mechanisms. The possible etiology of constipation in patients with diabetes is probably multifactorial, and includes both reversible and irreversible, and acute and chronic processes. There is strong evidence that despite being frequently linked to autonomic neuropathy, most of the gastrointestinal complications, including constipation, can be linked to poor glycemic control and less to the duration of the disease (37). Interestingly, constipation in diabetic patients does not correlate with autonomic neuropathy, indicating that neuropathy is not the principal mechanism causing constipation in these patients.

Both hyperglycemia and hypoglycemia were shown in acute and chronic studies to impair functioning of enteric neuronal regulation and to cause constipation (38). This suggests that in patients with diabetes and constipation, optimizing glycemic control should be the first priority.

The exact mechanisms involved in the development of constipation in patients with diabetes are poorly understood; however, one principal mechanism seems to be the loss of functional ICC $(39,40)$. 
ICC are the pacemaker cells in the gastrointestinal tract, and are crucially involved in the initiation and coordination of phasic and propagating contractions. Another function of the ICC is the control of neuronal input from nerves to smooth muscle cells for both excitatory and inhibitory neuronal input. More descriptive studies (41) found that in patients with diabetes, numerical changes in the number of ICC, and of excitatory and inhibitory neurons exist; however, the functional consequences of these numerical changes have yet to be determined.

Another mechanism discussed in the pathophysiology of diabetic constipation is smooth muscle myopathy caused by diabetes that impairs gastrointestinal motility and results in delayed gastrointestinal transit. Additionally, neuroendocrine imbalances can cause delayed gastrointestinal transit and contribute to the development of constipation in patients with diabetes. It remains speculative as to what extent additional mechanisms, including autoimmune damage, alterations of neuronal and smooth muscular trophic factors and apoptosis, contribute to the development of constipation; these potential mechanisms are subject to ongoing studies (42). All of the above-mentioned mechanisms are involved to some extent in gastrointestinal dysfunction in patients with diabetes, and result in impaired motor function including changes in complex motor functions such as the peristaltic reflex, sphincter tone and intestinal segmentation $(42,43)$.

\section{Neurogenic bowel dysfunction in patients with spinal cord injury, multiple sclerosis and Parkinson's disease}

Spinal cord injury, multiple sclerosis and Parkinson's disease are frequently associated with constipation. The origin of constipation in patients with these conditions is complex and include disease-related autonomic and pelvic nerve dysfunction as well as generalized systemic factors. The systemic factors include a broad variety ranging from altered solid and liquid diet and behaviour, impaired mobility and psychological disturbances. Furthermore, drugs used in the treatment of these conditions may also cause constipation; regular use of laxatives in these patients is advisable.

In patients with multiple sclerosis, bowel dysfunction including fecal incontinence and constipation is common. These symptoms frequently coexist, with bowel dysfunction occurring in up to $70 \%$ of patients with the disease $(44,45)$.

Little is known about the pathophysiology of bowel dysfunction in patients with multiple sclerosis. Small studies identified that colonic activity is reduced and transit time may be delayed, indicating that it is largely impaired colonic motility that causes the constipation (46). Treatment of constipation in these patients follows a purely symptomatic approach. When treating constipation in patients with multiple sclerosis, spastic disorders of the pelvic floor should be ruled out because these patients will probably not respond to treatment with laxatives.

Another neurological disorder frequently associated with gastrointestinal dysfunction is Parkinson's disease. Gastrointestinal symptoms are common and include dysphagia, esophageal dysmotility and, most commonly, constipation. Whereas dysphagia and esophageal dysmotility occur with advanced disease, constipation may occur early in the course of Parkinson's disease and sometimes even precedes the motor manifestations (47). The pathophysiology of constipation in Parkinson's disease includes central and peripheral mechanisms. Central mechanisms include changes in dorsal vagal nucleus function, although there is no clear correlation between the degree of cell loss or Lewy body counts in the dorsal vagal nucleus and the severity of constipation in patients with Parkinson's disease (48). At a peripheral site, the loss of dopaminergic neurons contributes to constipation; however, consequent dopaminergic treatment rarely alleviates constipation in patients with Parkinson's disease.

\section{SUMMARY}

Constipation is common and is caused by a wide variety of primary and secondary etiologies. Especially for severe cases, understanding the approach to primary causes is worthwhile to direct therapy and improve symptoms.

CONFLICTS OF INTEREST: Dr C Andrews has acted as a consultant, advisory board member and has received honoraria from Janssen, Inc. Dr Martin Storr has no financial disclosures or conflicts of interest to declare.

\section{REFERENCES}

1. Brandt LJ, Prather CM, Quigley EM, Schiller LR, Schoenfeld P, Talley NJ. Systematic review on the management of chronic constipation in North America. Am J Gastroenterol 2005;100(Suppl 1):S5-S21.

2. Higgins PD, Johanson JF. Epidemiology of constipation in North America: A systematic review. Am J Gastroenterol 2004;99:750-9.

3. Pare P, Ferrazzi S, Thompson WG, Irvine EJ, Rance L. An epidemiological survey of constipation in Canada: Definitions, rates, demographics, and predictors of health care seeking. Am J Gastroenterol 2001;96:3130-7.

4. Sleisenger MH, Feldman M, Friedman LS, Brandt LJ. Sleisenger \& Fordtran's Gastrointestinal and Liver Disease: Pathophysiology, Diagnosis, Management, 8th edn. Philadelphia: Saunders, 2006:2127-46.

5. Sleisenger MH, Feldman M, Friedman LS, Brandt LJ. Sleisenger \& Fordtran's Gastrointestinal and Liver Disease: Pathophysiology, Diagnosis, Management. 8th ed, Philadelphia: Saunders, 2006:2111-26.

6. Southwell BR, Clarke MC, Sutcliffe J, Hutson JM. Colonic transit studies: Normal values for adults and children with comparison of radiological and scintigraphic methods. Pediatr Surg Int 2009;25:559-72.

7. Dinning PG, Smith TK, Scott SM. Pathophysiology of colonic causes of chronic constipation. Neurogastroenterol Motil 2009;21:20-30.

8. Grundy D, Al-Chaer ED, Aziz Q, et al. Fundamentals of neurogastroenterology: Basic science. Gastroenterology 2006;130:1391-411.

9. Bharucha AE. Pelvic floor: Anatomy and function. Neurogastroenterol Motil 2006;18:507-19.

10. Rao SS. Advances in diagnostic assessment of fecal incontinence and dyssynergic defecation. Clin Gastroenterol Hepatol 2010;8:910-9.

11. Hinton JM, Lennard-Jones JE, Young AC. A new method for studying gut transit times using radioopaque markers. Gut 1969;10:842-7.

12. Rao SS, Camilleri M, Hasler WL, et al. Evaluation of gastrointestinal transit in clinical practice: Position paper of the American and European Neurogastroenterology and Motility Societies. Neurogastroenterol Motil 2011;23:8-23.

13. Burton DD, Camilleri M, Mullan BP, Forstrom LA, Hung JC. Colonic transit scintigraphy labeled activated charcoal compared with ion exchange pellets. J Nucl Med 1997;38:1807-10.

14. Camilleri M, Thorne NK, Ringel Y, et al. Wireless pH-motility capsule for colonic transit: Prospective comparison with radiopaque markers in chronic constipation. Neurogastroenterol Motil 2010;22:874-82,e233.

15. Cash BD, Chey WD. Review article: The role of serotonergic agents in the treatment of patients with primary chronic constipation. Aliment Pharmacol Ther 2005;22:1047-60.

16. Longstreth GF, Thompson WG, Chey WD, Houghton LA, Mearin F, Spiller RC. Functional bowel disorders. Gastroenterology 2006;130:1480-91.

17. Ashraf W, Park F, Lof J, Quigley EM. An examination of the reliability of reported stool frequency in the diagnosis of idiopathic constipation. Am J Gastroenterol 1996;91:26-32.

18. Tack J, Muller-Lissner S. Treatment of chronic constipation: Current pharmacologic approaches and future directions. Clin Gastroenterol Hepatol 2009;7:502-8; quiz 496. 
19. Preston DM, Lennard-Jones JE. Severe chronic constipation of young women: 'Idiopathic slow transit constipation'. Gut 1986;27:41-8.

20. Bassotti G, Roberto GD, Sediari L, Morelli A. Toward a definition of colonic inertia. World J Gastroenterol 2004;10:2465-7.

21. He CL, Burgart L, Wang L, et al. Decreased interstitial cell of Cajal volume in patients with slow-transit constipation. Gastroenterology 2000;118:14-21.

22. Tzavella K, Riepl RL, Klauser AG, Voderholzer WA, Schindlbeck NE, Muller-Lissner SA. Decreased substance P levels in rectal biopsies from patients with slow transit constipation. Eur J Gastroenterol Hepatol 1996;8:1207-11.

23. Knowles CH, De Giorgio R, Kapur RP, et al. The London Classification of gastrointestinal neuromuscular pathology: Report on behalf of the Gastro 2009 International Working Group. Gut 2010;59:882-7.

24. Nyam DC, Pemberton JH, Ilstrup DM, Rath DM. Long-term results of surgery for chronic constipation. Dis Colon Rectum 1997;40:273-9.

25. Remes-Troche JM, Rao SS. Neurophysiological testing in anorectal disorders. Expert Rev Gastroenterol Hepatol 2008;2:323-35.

26. Rao SS. Dyssynergic defecation and biofeedback therapy. Gastroenterol Clin North Am 2008;37:569-86, viii.

27. Loening-Baucke V. Encopresis and soiling. Pediatr Clin North Am 1996;43:279-98.

28. Rao SS, Ozturk R, Laine L. Clinical utility of diagnostic tests for constipation in adults: A systematic review. Am J Gastroenterol 2005;100:1605-15.

29. Rao SS. Biofeedback therapy for constipation in adults. Best Pract Res Clin Gastroenterol 2011;25:159-66.

30. Storr M, Allescher HD. [Motility-modifying drugs]. Internist (Berl) 2000;41:1318-24, 26-30.

31. Fosnes GS, Lydersen S, Farup PG. Constipation and diarrhoea common adverse drug reactions? A cross sectional study in the general population. BMC Clin Pharmacol 2011;11:2.

32. Simonson W, Han LF, Davidson HE. Hypertension treatment and outcomes in US nursing homes: Results from the US National Nursing Home Survey. J Am Med Dir Assoc 2011;12:44-9.

33. Dolder C, Nelson M, Stump A. Pharmacological and clinical profile of newer antidepressants: Implications for the treatment of elderly patients. Drugs Aging 2010;27:625-40.

34. Talley NJ, Jones M, Nuyts G, Dubois D. Risk factors for chronic constipation based on a general practice sample. Am J Gastroenterol 2003;98:1107-11.

35. Rosti G, Gatti A, Costantini A, Sabato AF, Zucco F. Opioid-related bowel dysfunction: Prevalence and identification of predictive factors in a large sample of Italian patients on chronic treatment. Eur Rev Med Pharmacol Sci 2010;14:1045-50.

36. Mjornheim AC, Finizia C, Blohme G, Attvall S, Lundell L, Ruth M. Gastrointestinal symptoms in type 1 diabetic patients, as compared to a general population. A questionnaire-based study. Digestion 2003;68:102-8.

37. Clouse RE, Lustman PJ. Gastrointestinal symptoms in diabetic patients: Lack of association with neuropathy. Am J Gastroenterol 1989;84:868-72.

38. Takahashi T, Matsuda K, Kono T, Pappas TN. Inhibitory effects of hyperglycemia on neural activity of the vagus in rats. Intensive Care Med 2003;29:309-11.

39. He CL, Soffer EE, Ferris CD, Walsh RM, Szurszewski JH, Farrugia G. Loss of interstitial cells of Cajal and inhibitory innervation in insulin-dependent diabetes. Gastroenterology 2001;121:427-34.

40. Horvath VJ, Vittal H, Lorincz A, et al. Reduced stem cell factor links smooth myopathy and loss of interstitial cells of Cajal in murine diabetic gastroparesis. Gastroenterology 2006;130:759-70.

41. Ordög T. Interstitial cells of Cajal in diabetic gastroenteropathy. Neurogastroenterol Motil 2008;20:8-18.

42. Verne GN, Sninsky CA. Diabetes and the gastrointestinal tract. Gastroenterol Clin North Am 1998;27:861-74, vi-vii.

43. Sellin JH, Chang EB. Therapy insight: Gastrointestinal complications of diabetes - pathophysiology and management. Nat Clin Pract Gastroenterol Hepatol 2008;5:162-71.

44. Glick ME, Meshkinpour H, Haldeman S, Bhatia NN, Bradley WE. Colonic dysfunction in multiple sclerosis. Gastroenterology 1982;83:1002-7.

45. Hinds JP, Wald A. Colonic and anorectal dysfunction associated with multiple sclerosis. Am J Gastroenterol 1989;84:587-95.

46. Preziosi G, Emmanuel A. Neurogenic bowel dysfunction: Pathophysiology, clinical manifestations and treatment. Expert Rev Gastroenterol Hepatol 2009;3:417-23.

47. Abbott RD, Petrovitch H, White LR, et al. Frequency of bowel movements and the future risk of Parkinson's disease. Neurology 2001;57:456-62.

48. Cersosimo MG, Benarroch EE. Neural control of the gastrointestinal tract: Implications for Parkinson disease. Mov Disord 2008;23:1065-75.

49. Dinning PG, Szczesniak MM, Cook IJ. Twenty-four hour spatiotemporal mapping of colonic propagating sequences provides pathophysiological insight into constipation. Neurogastroenterol Motil 2008;20:1017-21. 


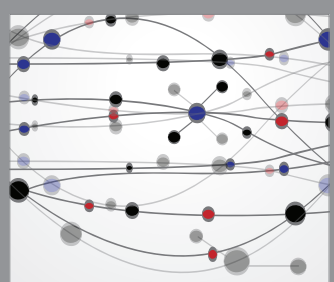

The Scientific World Journal
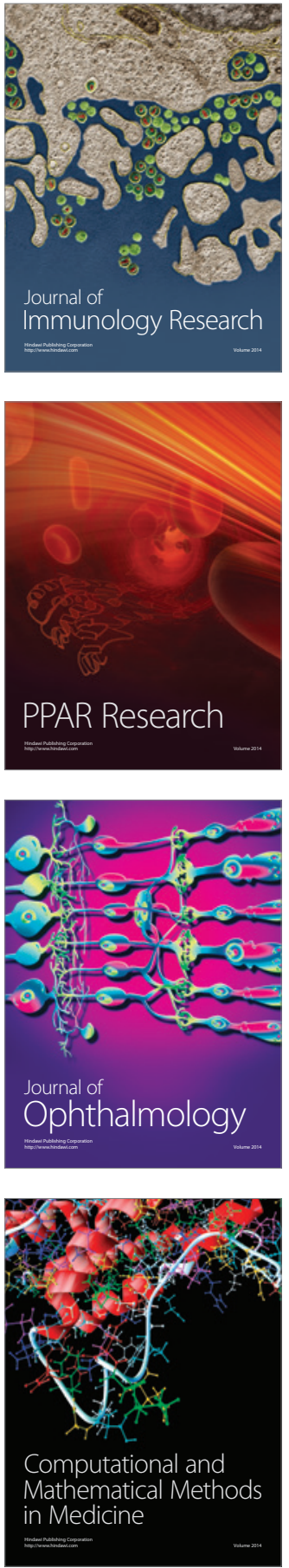

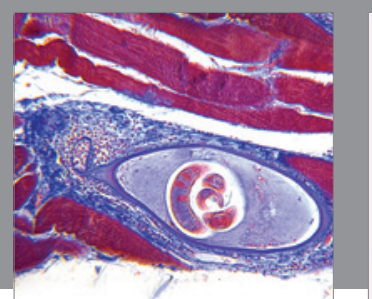

Gastroenterology Research and Practice

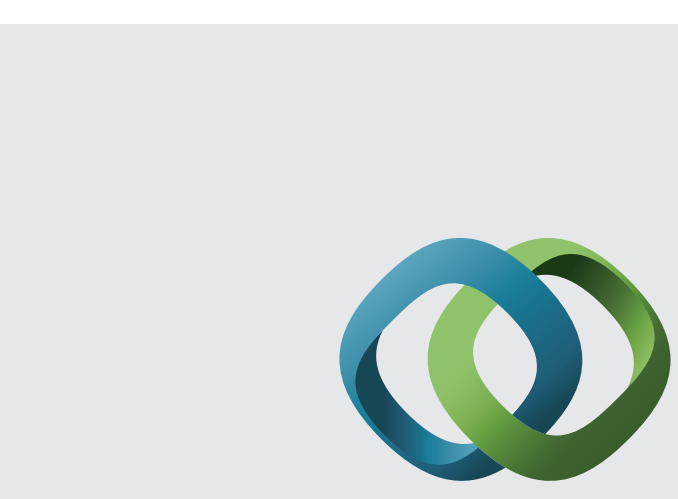

\section{Hindawi}

Submit your manuscripts at

http://www.hindawi.com
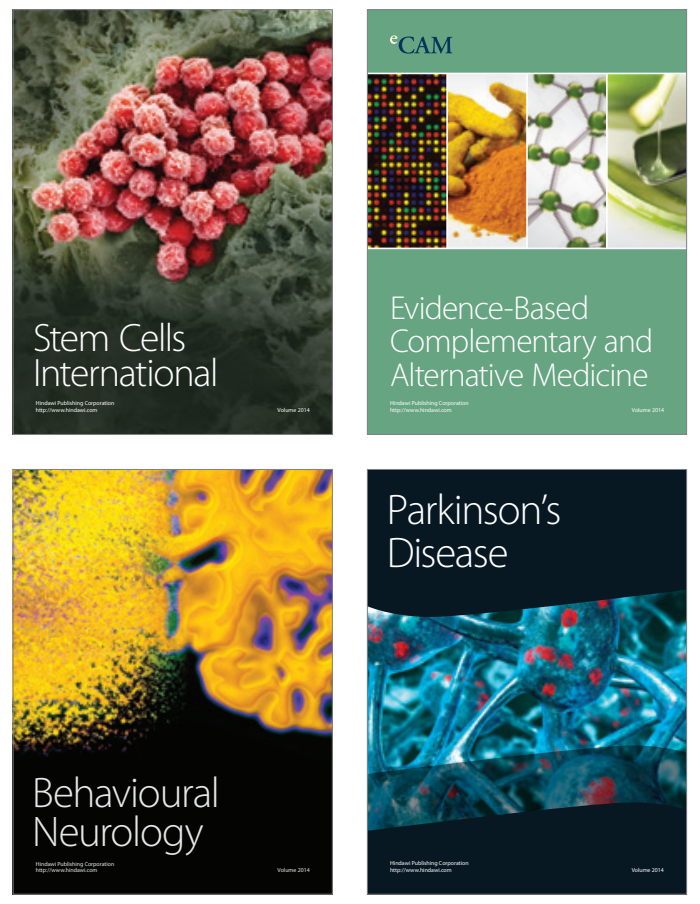
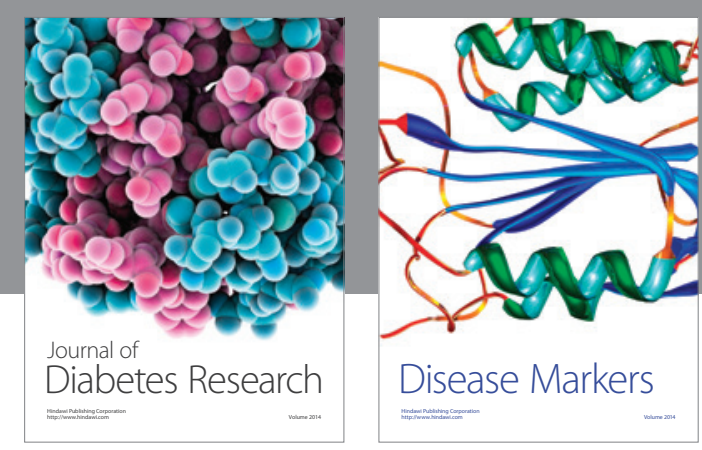

Disease Markers
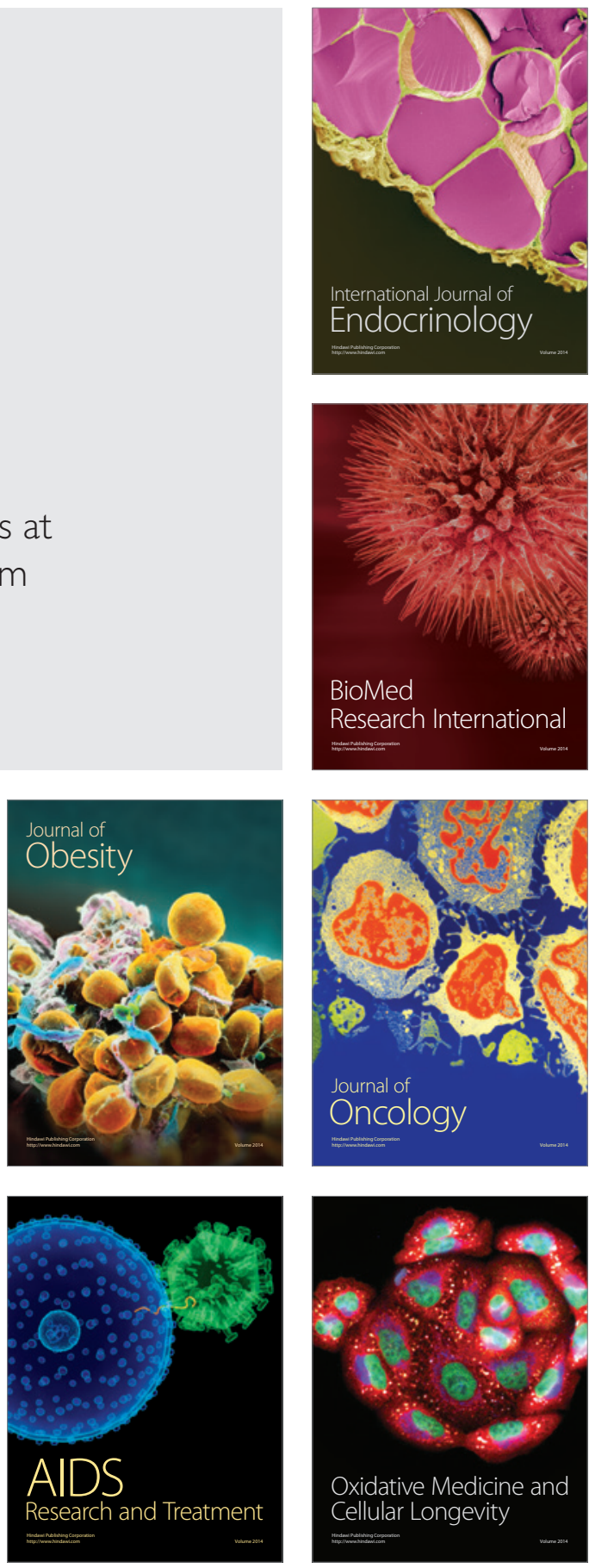